\title{
A Machine Approach for Field Weakening of Permanent- Magnet Motors
}

\author{
John S. Hsu
}

*Oak Ridge National Laboratory

Copyright $\odot 1998$ Society of Automotive Engineers, Inc.

\begin{abstract}
The commonly known technology of field weakening for permanent-magnet (PM) motors is achieved by controlling the direct-axis current component through an inverter. Without using mechanical variation of the air gap, a new machine approach for field weakening of PM machines by direct control of air-gap fluxes is introduced. The demagnetization situation due to field weakening is not an issue with this now method. In fact, the PMs are strengthened at field weakening. The field-weakening ratio can reach 10:1 or higher. This technology is particularly useful for the PM generators and electric vehicle drives.
\end{abstract}

\section{INTRODUCTION}

When a vehicle is cruising at high speed, the required torque is normally low, and the supply voltage to the motor has a certain limit. Therefore, field weakening is an essential requirement for motors used for electric vehicle drive. The field weakening can be obtained easily for an induction motor when its supply frequency is increased without proportionally increasing the motor terminal voltage. On the contrary, from the word "permanent," the motor terminal voltage may not easily be reduced when the supply frequency goes up. The field weakening is not an inherent property of PM motors. Various relatively complex approaches for obtaining field weakening of PM motors exist. For PM generators, if their field can be controlled, the need of using a buck-boost converter to control the generator output voltage measured at the direct current (DC) link and then using the inverter to change back to alternating current could be eliminated.

There are ideas on adjusting the air gap mechanically for field weakening of PM motors.
However, their mechanical instability may cause a certain concern.

Chan et al. [1] introduced the use of transformer electromotive force (emf) to oppose the rotational emf by purposely producing a slope on the armature current. Certain torque ripples would be generated.

Sebastian and Slemon proposed that with optimum alignment of the stator and magnet fields, maximum torque per ampere is achieved up to a break-point speed [2]. Operation at higher speeds with reduced torque is achieved by adjustment of the current angle to reduce the effective magnet flux (i.e., the equivalent of field weakening).

Sozer and Torrey [3] presented an approach for adaptive control of the surface mount PM motor over its entire speed range. The adaptive fluxweakening scheme is able to determine the right amount of direct-axis current at any operating condition.

Namuduri and Murty [4] focused their discussion on the pulse-width-modulation (PMM) strategy and the microcontroller system that implements the phase-angle control scheme. The authors concluded that though the PM motors were not designed for field weakening by phase-angle control, experiments showed that the torque at no-load speed can be increased significantly with phase advance, at the expense of increased motor losses.

Soong and Miller [5] based their study on the work by Morimoto et al. [6] for the maximum torque field-weakening control. They concluded that the optimal high-saliency interior PM motor design is the most promising for applications requiring a wide fieldweakening range.

\footnotetext{
*Prepared by the Oak Ridge National Laboratory, Oak Ridge, Tennessee 37831, managed by Lockheed Martin Energy Research Corp. for the U. S. Department of Energy under contract DE-AC05-960R22464.

The submitted manuscript has been authored by a contractor of the U. S. Government under contract No. DE-AC05-960R22464. Accordingly, the U. S. Government retains a nonexclusive, royalty-free license to publish or reproduce the published form of this contribution, or allow others to do so, for U. S. Government purposes.
} 
Morimoto et al. again stated that in the PM motor, direct control of the magnet flux is not available. However, the direct-axis armature current can weaken the air-gap flux. In their operation, magnet demagnetization due to the direct axis armature reaction must be prevented because the magnet torque decreases irreversibly if this demagnetization is very large.

This study suggests a new direct control of the air-gap flux of PM machines through the magnitude and polarity of the DC control current fed to a fieldweakening control coil [7]. The power electronic control of direct and quadrature-axis current components, which is demanded by the entire existing field weakening technologies, is not required. Subsequently, a position sensor is not necessary for the inverter control. Under a normal control range, the field-weakening control coil does not introduce a situation of demagnetizing the PMs. Contrary to the existing technology, the PMs are strengthened at field weakening. A 10:1 field-weakening ratio can easily be obtained. This new method is robust and particularly useful for, but not limited to, PM generators and electric vehicle drives. The same principle can be used for either axial- or radial-gap PM machines.

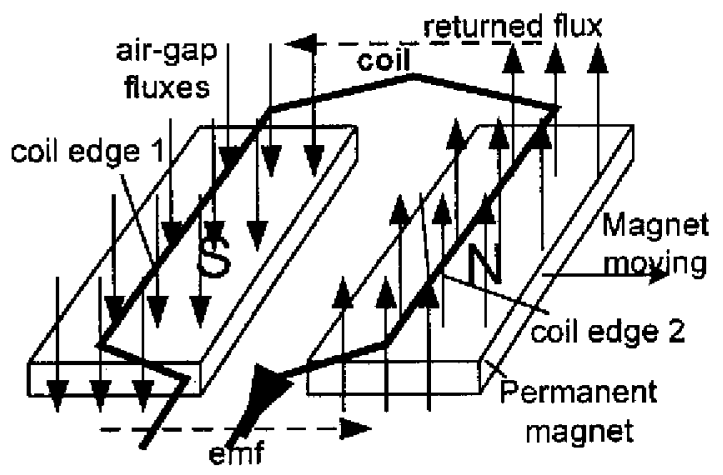

(a) Normal situation

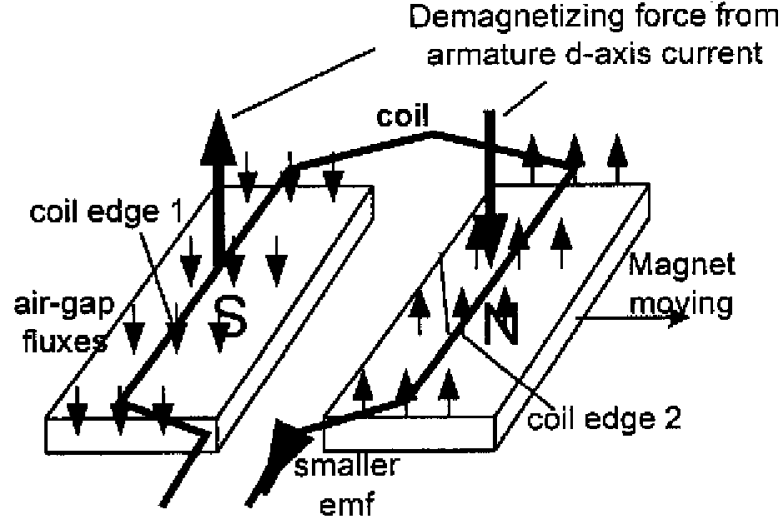

(b) Conventional field weakening

Fig. 1. Conventional field weakening.

\section{CONVENTIONAL FIELD WEAKENING BY DIRECT- AXIS CURRENT COMPONENT}

Fig. fa shows the conventional situation of a coil in a PM machine where the air-gap fluxes of opposite polarities are acting on the coil edges 1 and 2 . A back emf is induced when there is a relative movement between the coil and the air-gap fluxes. Fig. ib shows that for a conventional PM machine field weakening, the direct-axis current component weakens the field. The magnitudes of the air-gap fluxes at both coil edges are equally weakened in opposite polarities. Subsequently, a smaller back emf is induced. The direct-axis current component is obtained through a power electronic circuit that is capable of handling a full-load rating.

\section{NEW PRINCIPLE OF EQUALIZATION OF AIR-GAP FLUX DENSITIES FOR FIELD WEAKENING}

The principle of equalization of air-gap flux densities for field weakening of the new type of PM machines is explained in Fig. 2.
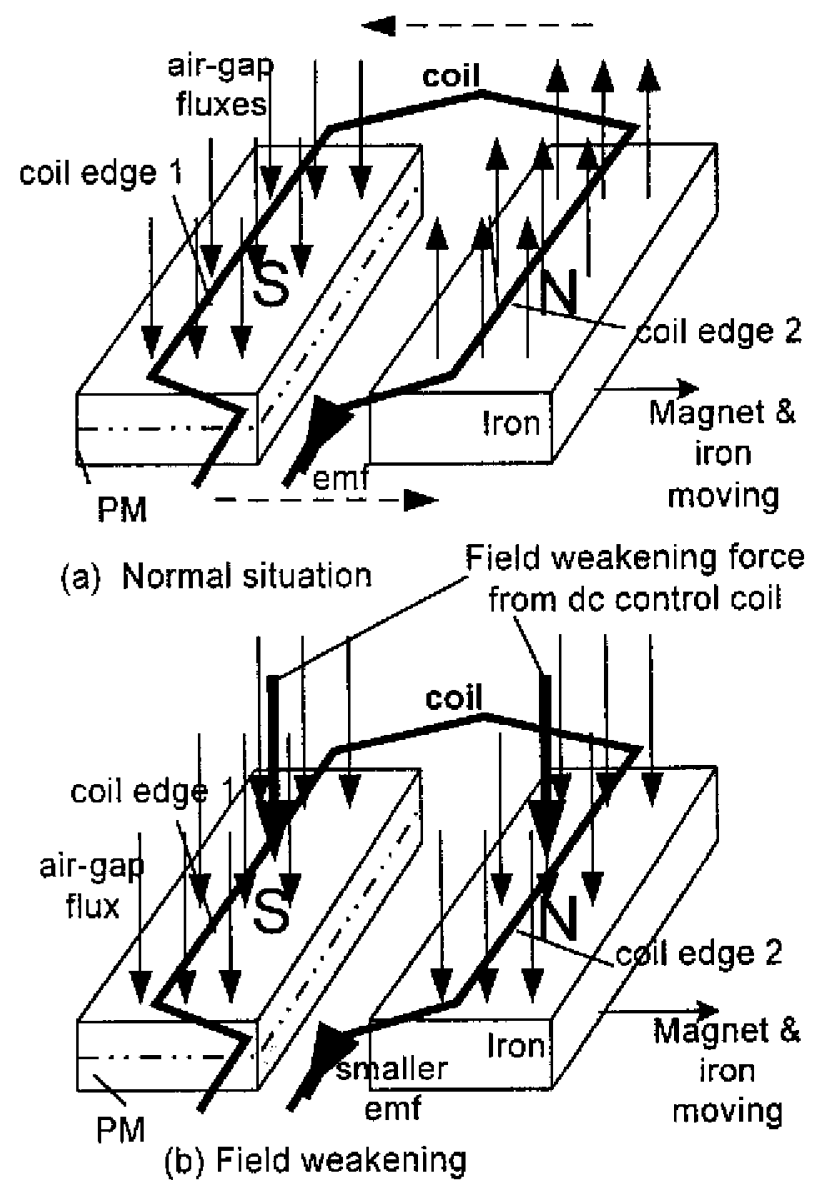

Fig. 2. Direct control of air-gap flux of PM machine. 
Fig. 2 shows an example that explains the new field-weakening technology. Compared to Fig. 1, the PM acting on coil edge 2 is removed and added to the thickness of the PM acting on coil edge 1 . The total thickness of PM per pole pair remains unchanged. An iron piece that has no polarity on its own is placed in the vacant position. Fig. 2a shows that when all the flux is restricted to go from one pole to the other, the air-gap flux density remains the same as that shown in Fig. 1a. Fig. $2 b$ shows that when a $D C$ control field acts on the PM and the iron, the air-gap flux densities acting on the two coil edges tend to be equalized. Subsequently, the induced emf is reduced. The PM is strengthened under this field-weakening situation.

The waveform of the back emf of a coil edge is a reflection of the air-gap flux distribution of a pole that the coil edge is under. The properly shaped poles and air gaps and the distribution and pitch factors can be used for harmonic reduction.

\section{PROTOTYPE MACHINE}

The upper drawing of Fig. 3 shows a cut view of a four-pole prototype machine, and the lower drawing shows the rotor. The rotor of this particular prototype machine is sandwiched between two axial-gap stators. Two of the rotor poles are made of mild steel. The other two poles are made of PMs. These two PM poles have the same polarity with a thickness sufficient for pushing the air-gap fluxes through the PMs and the mildsteel poles to form a complete magnetic path. The poles are mounted in an aluminum rotor structure that is attached to a nonmagnetic shaft made of stainless steel. The round shape of the PMs and the ferromagnetic poles results from the use of available round PMs to fill a normal pole shape shown in dotted lines. It is expected that the use of two round PMs per pole may cause harmonics in the back emf. However, a pole cap that follows the dotted line of a rotor pole shown in Fig. 3 is placed on top of the round PMs to reduce the air-gapflux harmonics. More appropriate magnet geometry should be used in a real design.

Two field-weakening control coils wound in toroidal shapes are placed between the stator winding and the steel supporting frame of the machine. They are approximately 100 turns each. Like a field coil of a DC machine, more turns of the field-weakening control coils require less excitation current. Normally, the field coil power is a very small percentage of the total power of a DC machine. The prototype stator has 12 slots, and the coils are of full pitch with one coil per pole per phase.

The steel support frame of the machine is made of $1 / 2$ in. mild steel. It is expected that the thickness of a round steel frame would be significantly reduced because the peripheral of a frame is about three times the outer diameter of a machine.
Field

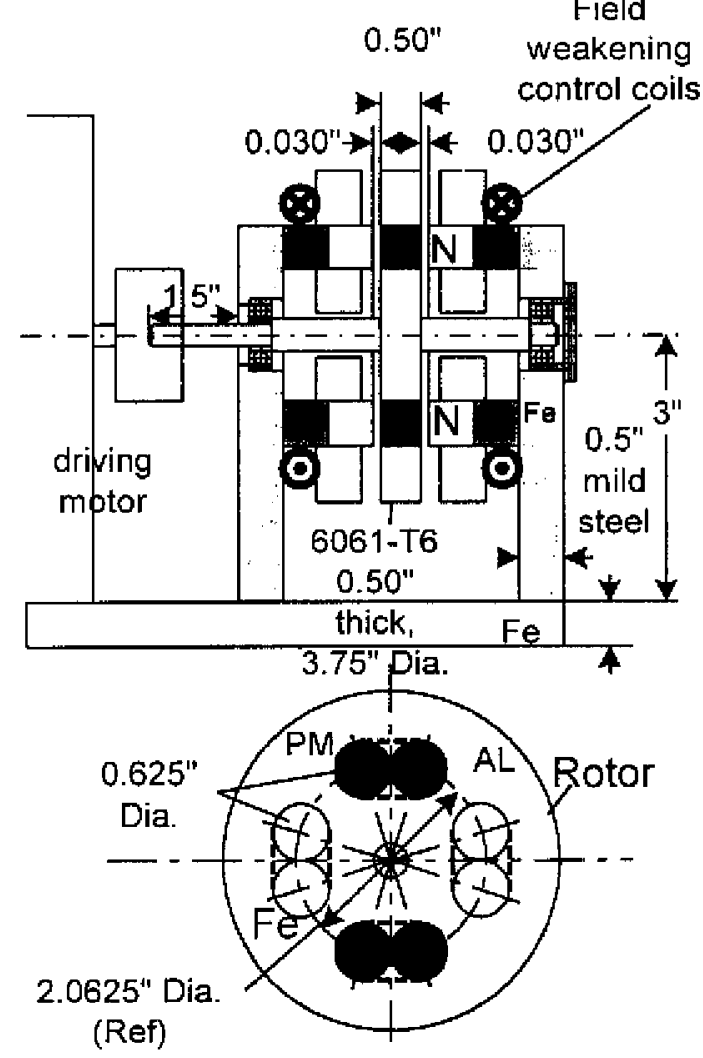

Fig. 3. A prototype PM machine for testing back emf of the direct control of air-gap flux of the new PM machine.

Fig. 4 shows the picture of an actual prototype motor driven by a low-speed motor for back emf measurement. in order to measure the back emf of the stator armature winding, the rotor of the prototype machine is driven by a small motor of roughly $1200 \mathrm{rpm}$.

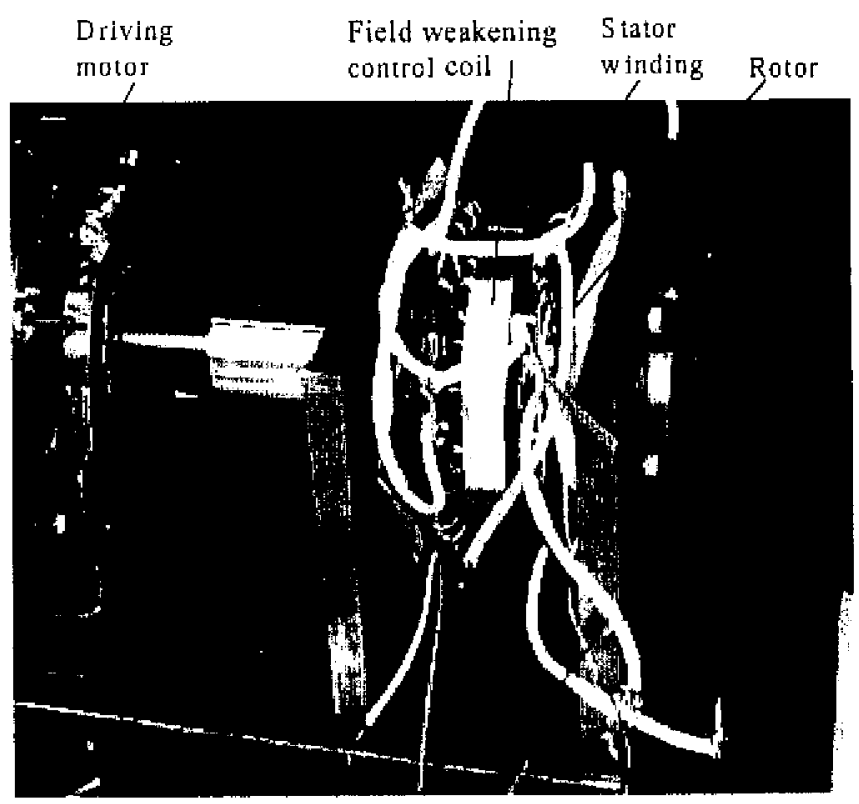

Fig. 4. A prototype PM motor with direct control of airgap flux. 
The driving motor is shown on the left-hand side of Figs. 3 and 4 . The two axial-gap stators were originally designed for a 50,000-rpm high-speed PM motor. It is understandable that a low voltage would be generated when a low-speed motor drives the rotor.

\section{TEST RESULTS}

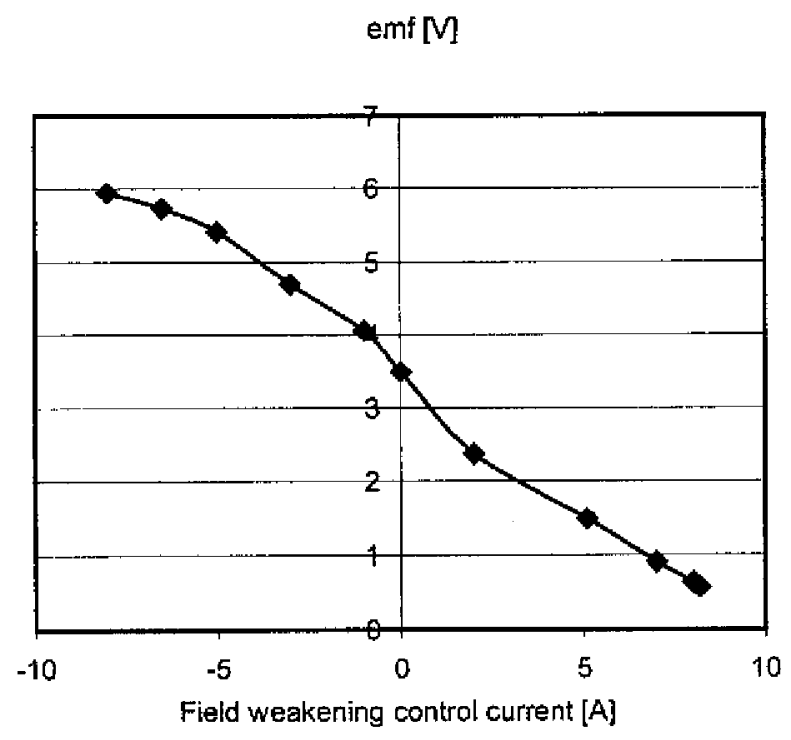

Fig. 5. Tested back emf values versus control currents of the field-weakening coil.

Fig. 5 shows the tested back emf values versus the control currents of the field-weakening coil. As mentioned before, because the driving motor runs at low speed, the back emf is expectedly low. Attention should be drawn to the ratio of the emf values that are changed from the maximum value to the minimum value. Test results show that a field-weakening ratio of $10: 1$ and higher can be obtained.

Fig. 6 shows the back emf of the prototype machine traces with pole caps under various field strengths. A significant field control capability is clearly observed.

\section{CONCLUSIONS}

- A new field-weakening and adjustment technology for PM machines is introduced.

- A 10:1 or higher field-weakening ratio can be obtained.

- The air-gap fluxes are controlled directly by the fieldweakening control coils.

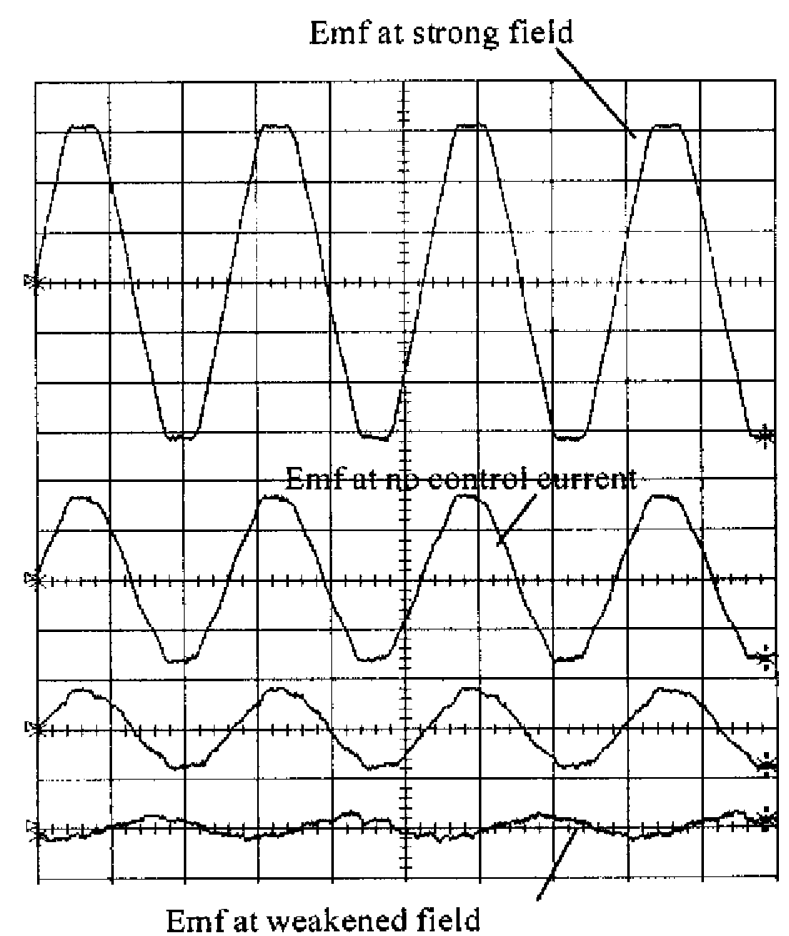

[10 $\mathrm{ms} / \mathrm{div}, 2 \mathrm{~V} / \mathrm{div}]$

Fig. 6. Back emf traces under various field strengths.

- No control of the direct and quadrature-axis current components is necessary for the new PM machines. Therefore, the inverter and control are greatly simplified and no position sensor is required.

- Under a normal control range, the demagnetization due to field weakening is not an issue with this new technology.

- The PMs are strengthened under a field-weakening situation.

- This new technology is robust due to its simple operation principle.

- The same principle can be used for either axial or radial gap PM machines.

- This technology is particularly useful for, but not limited to, electric vehicle motor drives and PM generators.

\section{ACKNOWLEDGMENTS}

The author appreciates support funded by the Office of Advanced Automotive Technologies, U.S. Department of Energy. Encouragement from the Power Electronics \& Electric Machinery Research Center headed by Donald Adams, and the prototype building led by Michael Jenkins are gratefully acknowledged. 


\section{CONTACT}

John S. Hsu (Htsui) received a B.S. degree from Tsing-Hua University, Beijing, China, and a Ph.D. degree from Bristol University, England.

He worked in research and development areas for Newman Industry of England, Emerson Electric Company, and Westinghouse Electric Corporation. He served as head of the Rotating Machines and Power Electronics Program, Center for Energy Studies, the University of Texas at Austin for four years.

Currently, he is a senior staff scientist of the Power Electronics and Electric Machine Group, Oak Ridge National Laboratory. Dr. Hsu is the author or coauthor of more than one hundred technical papers and reports.

\section{REFERENCES}

[1] C. C. Chan, J. Z. Jiang, W. Xia, and K. T. Chau, "Novel Wide Range Speed Control of Permanent Magnet Brushless Motor Drives," pp. 539-546, IEEE Transactions on Power Electronics, vol. 10, No. 5, Sept. 1995.

[2] T. Sebastian and G. R. Slemon, "Operating Limits of Inverter-Driven Permanent Magnet Motor Drives," pp. 800-805, CH2272-3/86, IEEE.
[3] Y. Sozer and D. A. Torrey, "Adaptive Flux Weakening Control of Permanent Magnet Synchronous Motors," pp. 475-482, Conference Record, 1998 IEEE Industry Applications Conference, Vol. 1, 12-15, October 1998, St. Louis, Missouri.

[4] C. S. Namuduri and B. V. Murty, "High Power Density Electric Drive for an Hybrid Electric Vehicle," Conference Proceedings, APEC ' 98 , Vol. 1, p.p. $34-40,98 \mathrm{CH} 36154$, February 15-19, 1998, The Disneyland Hotel, Anaheim, California.

[5] W. L. Soong and T. J. E. Miller, "Field-Weakening Performance of Brushless Synchronous AC Motor Drives," pp. 331-340, IEE Proc-Electr. Power Appl., Vol. 141, No. 6, November 1994.

[6] S. Morimoto, Y. Takeda, T. Hirasa, and K. Taniguchi, "Expansion of Operating Limits for Permanent Magnet by Current Vector Control Considering Inverter Capacity," pp. 866-871, IEEE Transactions on Industry Applications, Vol. 26, No. 5, September/October 1990.

[7] John S. Hsu, U.S. Patent Application, "Equalized Field Weakening of Permanent Magnet Motors and Generators," filed January 21,1999 , in the U.S. Patent and Trademark Office at Reel 9724 and Frame 0131. 